\title{
Subarachnoid haemorrhage: a cause of left bundle branch block?
}

\author{
S. Dubrey*, T.Y. Huehns* and A.P. Brooks \\ Royal Hampshire County Hospital, Winchester SO22 5DG, UK
}

\begin{abstract}
Summary: We describe what we believe to be the first reported case of documented de novo left bundle branch block in association with acute subarachnoid haemorrhage.
\end{abstract}

\section{Introduction}

Many electrocardiographic changes have been described in association with subarachnoid haemorrhage. The phenomenon was first reported in $1947 .{ }^{1}$ The development of de novo left bundle branch block has not previously been documented with subarachnoid haemorrhage.

\section{Case report}

A 77 year old man attended the Accident and Emergency Department with an episode of presyncope. He reported dizziness, nausea and mild neck discomfort. There was no history of palpitations, chest pain or headache and before this he had been feeling completely well. He was a non-insulindependent diabetic controlled on diet, with no hypertension or previous cardiac history.

On examination the patient was pale, sweaty and was retching. He was apyrexial and normotensive, with a regular pulse of 88 beats per minute. He had no neurological signs, papilloedema or neck stiffness. Initial investigations, including a full blood count, urea and electrolytes and liver function tests were all normal, as was a chest X-ray and an electrocardiogram (Figure 1).

He was admitted for observation, continuous electrocardiographic monitoring and cardiac enzyme measurements. He was treated with bed rest, oral analgesia (paracetamol $1 \mathrm{~g}$ and dihydrocodeine $20 \mathrm{mg}$ in combination, four times daily) and an intravenous anti-emetic (metoclopramide

Correspondence: $\quad$ S. Dubrey, $\quad$ B.Sc., M.R.C.P., D.R.C.O.G., Academic Medicine, Chelsea and Westminster Hospital, 369 Fulham Road, London SW10 9NH, UK.

*Currently Research Fellows, Academic Medicine, Chelsea and Westminster Hospital, 369 Fulham Road, London SW10 9NH, UK.

Accepted: 4 January 1994
$10 \mathrm{mg}$ three times daily). Serial cardiac enzymes were subsequently documented to be normal and he had no arrhythmias on monitoring.

On the day following admission, he developed a severe headache and profuse vomiting. There was now marked meningism, with neck stiffness and exaggerated reflexes. The electrocardiogram now showed left bundle branch block, with a\& $\overrightarrow{0}$ unchanged axis, in sinus rhythm at a rate of 68 beats per minute (Figure 2). His blood pressure wa now $180 / 100 \mathrm{mmHg}$. An urgent computerise tomographic brain scan showed no abnormalities before and after intravenous contrast. At lumbar puncture the cerebrospinal fluid was xanthochromic, with slightly increased white cells, grossly raised red cells and high protein. Culture revealed no bacterial growth.
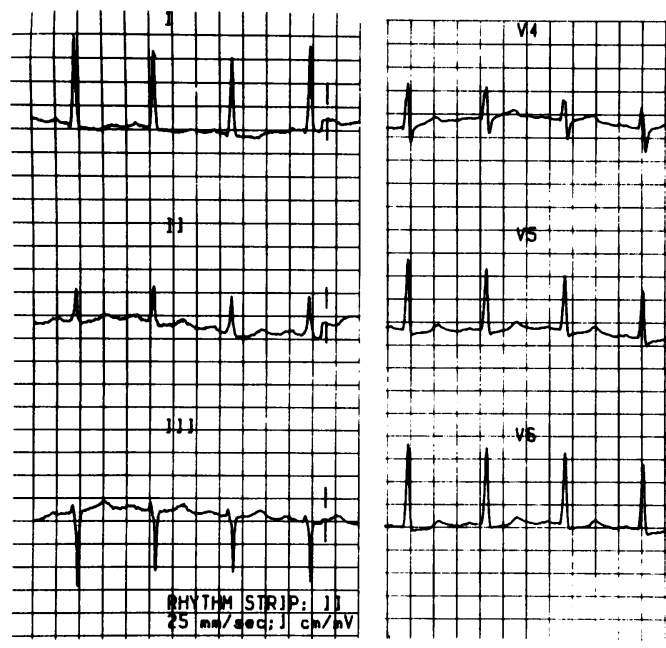

Figure 1 Electrocardiogram on admission, with no atrio-ventricular delay. QRS duration 100 milliseconds, sinus rhythm $88 /$ minute, axis $-20^{\circ}$. 

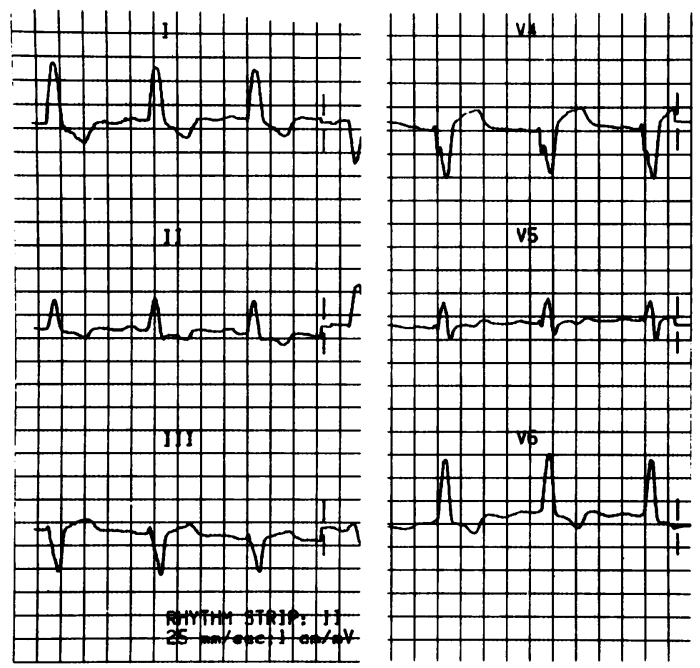

Figure 2 Electrocardiogram 20 hours after admission, showing left bundle branch block. QRS duration 200 milliseconds, sinus rhythm $68 /$ minute, axis $-20^{\circ}$.

A diagnosis of subarachnoid haemorrhage was made and conservative management was chosen. Anti-hypertensive treatment with a calcium channel blocker (nifedipine slow release $10 \mathrm{mg}$ twice daily) was initiated following the lumbar puncture. The patient made an uneventful recovery, antihypertensive treatment was stopped 2 days before discharge and the patient left the hospital a total of 10 days after admission. At out-patient follow-up 6 weeks later he was well, normotensive on no current treatment and his electrocardiogram indicated persistence of the left bundle branch block pattern.

\section{Discussion}

It is well known that subarachnoid haemorrhage produces cardiac and pulmonary abnormalities. ${ }^{2}$ Cardiac arrhythmias have been documented in greater than $90 \%$ of cases of subarachnoid haemorrhage. ${ }^{3}$ Morphological abnormalities of the electrocardiogram have also been widely described, with changes occurring in at least $50 \%$ of cases. ${ }^{4}$ The findings on electrocardiography commonly exhibit 'ischaemic' features, such as ST-segment or T-wave changes, or U-wave abnormalities, but also include abnormal P waves, or changes in the PR or QT intervals. ${ }^{4}$ The cause of these electrical changes in subarachnoid haemorrhage is not fully understood, but it would appear to have a multi-factorial aetiology.

Intracranial events have been shown to result in both histologically visible myocardial necrosis and subendocardial haemorrhage; ${ }^{5,6}$ features that sug- gest structural cardiac damage as a cause for the electrocardiographic changes. Thallium myocardial scintigraphy has also suggested that myocardial perfusion is impaired in a proportion of cases with abnormal electrocardiograms after subarachnoid haemorrhage, ${ }^{7}$ thus implying that there is an ischaemic element to the electrocardiographic changes. However, a positive thallium scan was not related to any specific electrocardiographic feature. It is also important to note that none of these patients had had ischaemic heart disease excluded prior to the subarachnoid haemorrhage.

Animal work has shown that intracranial injection of blood gives rise to electrocardiographic changes, mainly $\mathrm{T}$-wave changes, in a proportion of cases, but not in all. ${ }^{8}$ In patients who have electrocardiographic abnormalities compared to those without, it has been demonstrated that there is increased excretion of catecholamine metabolites. ${ }^{9}$ The increased catecholamines may be caused by hypothalamic damage in subarachnoid haemorrhage. 9 Some of the electrocardiographic changes relating to the effects of the catecholamines are abolished by treatment with $\beta$-blocker ${ }^{10}$ but in clinical trials this treatment has not been beneficial. Other workers suggest that only sinus tachycardia and $\mathrm{T}$-wave inversion are associated with raised catecholamines. ${ }^{11}$ It is implied that at least some of the recognized electrocardiographic changes are secondary to changes in catecholamine levels.

In two previous articles, bundle branch block has been associated with subarachnoid haemorrhage but, in both of these reports no premorbid electrocardiograms were quoted, and therefore it is not clear whether the bundle branch block was a new development. ${ }^{12,13}$ In contrast, the patient that we have reported clearly had a normal electrocardiogram on admission with mild non-specific symptoms. The left bundle branch block occurred when the symptoms became more classical of a subarachnoid haemorrhage. The clinical signs supported this diagnosis, which was ultimately confirmed by the lumbar puncture findings.

Left bundle branch block occurs as a result of delayed conduction within the left bundle of His. It usually indicates the presence of significant cardiac disease and is a strong predictor of cardiac mortality. ${ }^{14}$ It is unlikely that a coincidental cardiac event occurred in this patient to cause the left bundle branch block because there were no symptoms to suggest myocardial ischaemia and a normal cardiac enzyme series was recorded. Development of left bundle branch block can also be rate-related ${ }^{14}$ but this was not true in this patient. It is concluded that the left bundle branch block was related to the subarachnoid haemorhage.

In summary we would like to add the development of left bundle branch block to the list of 
abnormal electrocardiographic findings associated with subarachnoid haemorrhage. The importance of excluding intracerebral pathology when present-

\section{References}

1. Byer, E., Ashman, R. \& Toth, L.A. Electrocardiograms with large upright $\mathrm{T}$ waves and long QT intervals. Am Heart $J$ 1947, 33: 796-806.

2. Walton, J. Disorders of the cerebral circulation. In: Brain's Diseases of the Nervous System. Ed. Walton, J. 9th ed. Oxford University Press, Oxford, 1985, pp. 183-225.

3. Andreoli, A., di Pasquale, G., Pinelli, G., Grazi, P., Tognetti, F. \& Testa, C. Subarachnoid haemorrhage: frequency and severity of cardiac arrhythmias. Stroke 1987, 18: 558-564.

4. Johnson, R.H., Lambie, D.G. \& Spalding, J.M.K. Neurogenic abnormalities of the heart. In: Neurocardiology: The Interrlationships between Dysfunction in the Nervous and Cardiovascular Systems. Ed. Walton, J. W.B. Saunders Company, London, 1984, pp.66-78.

5. Koskelo, P., Punsar, S. \& Sipila, W. Subendocardial haemorrhage and ECG changes in intracranial bleeding. $\mathrm{Br} \mathrm{Med} J$ 1964, 1: 1479-1480.

6. Kolin, A. \& Norris, J.W. Myocardial damage from acute cerebral lesions. Stroke 1984, 15: 990-993.

7. Szabo, M.D., Crosby, G., Hurford, W.E. \& Strauss, H.W. Myocardial perfusion following acute subarachnoid hemorrhage in patients with an abnormal electrocardiogram. Anesth Analg 1993, 76: 253-258.

8. Han, X. Continuous observation of the electrocardiogram following experimental cerebral hemorrhage. Chung-Hua Shan Ching Ching Shen Ko Tsa Chih 1991, 24: 295-296. ed with a patient with no obvious cardiac cause for an abnormal electrocardiogram should be reemphasized.

9. Cruickshank, J.M., Neil-Dwyer, G. \& Stott, A.W. Possible role of catecholamines, corticosteroids, and potassium in production of electrocardiographic abnormalities associated with subarachnoid haemorrhage. $\mathrm{Br}$ Heart $J$ 1974, 36: 697-706.

10. Cruickshank, J.M., Neil-Dwyer, G. \& Lane, J. The effect of oral propranolol upon the ECG changes occurring in $\mathrm{C}$ subarachnoid haemorrhage. Cardiovasc Res 1975, 9: $\overrightarrow{0}$ 236-245.

11. Grad, A., Kiauta, T. \& Osredkar, J. Effect of elevated plasma norepinephrine on electrocardiographic changes in subarachnoid hemorrhage. Stroke 1991, 22: 746-749.

12. Srivastava, S.C. \& Robson, A.O. Electrocardiographic abnormalities associated with subarachnoid haemorrhage. Lancet 1964, 2: 431-432.

13. Brouwers, P.J.A.M., Wijdicks, E.F.M., Hasan, D. et al. Serial electrocardiographic recording in aneurysmal subarachnoid hemorrhage. Stroke 1989, 20: 1162-1167.

14. Braunwald, E. Heart Disease: A Textbook of Cardiovascular Medicine, 4th ed. W.B. Saunders Company, Philadelphia, 1992. 